\title{
Method for processing experimental strength data using statistical methods
}

\author{
Valeriy Kasyanov ${ }^{1}$, Evgeny Kosenko ${ }^{1 *}$, Vera Kosenko ${ }^{1}$, Vasily Krymsky ${ }^{1}$ \\ ${ }^{1}$ Don State Technical University, 344010, Rostov-on-Don, Russia
}

\begin{abstract}
The selective calculation method has been successfully applied for several centuries due to its profitability. However, when calculating the failure-freeness in the case of fatigue fractures (often sudden), when there is a significant power relationship $\mathrm{m}=10-15$ for the super-cycle loading region between the strength (hardness, endurance limit) and the effective voltage, the reduction of the minimum component life will be 10-100 or more times. This is due to the unaccounted main part of the population. In our example, there are $104-50=9950$ units of such parts, i.e., their potential failures. Therefore, for this case, the selective method is an intermediate stage of calculations.
\end{abstract}

\section{Introduction}

Many years of experience in applying the selective method both in science and in engineering practice have proved to be beneficial: saving labor, material and time resources.

Typically sets of products and events are applied at various stages of life. This circumstance of finiteness of populations opens up new possibilities for statistical methods in science and engineering practice.

Sharing experience in the study and application of the theory and practice of products reliability (in particular machines), it can be argued that the selective method does not provide a complete picture when solving reliability problems [1-3].

So, for example, while collecting information on the reliability of construction, agricultural, transport and other machines during their operation in the Rostov Region and Krasnodar Territory since 1969, with long-term observations over 4-5 years for samples of 30-35 units, it was found that failures occur not only in the cars from the sampling.

It is known that the main damage to machine parts is wear and fatigue. The parameters of the parts during deterioration do not significantly affect the resource of the parts, usually to the extent of about 1 to 3 .

The most important circumstance when using the aggregate instead of the sample is the calculation of the fatigue life of machine parts: gears, shafts, metal structures, etc. [4].

\footnotetext{
* Corresponding author: a123lok@mail.ru
} 


\section{Results}

Fatigue is characterized by a significantly greater effect on the resource of the part: the strength (hardness, endurance limit have a close directly proportional relationship) of steel and the effective stress in the dangerous section of the part are connected by a degree of $\mathrm{m} 1$ $=3-8$ with its resource for the multi-cycle loading region [5].

For a super-cycle region, when a part must have a resource of more than 2-3 thousand hours and work out more than (2-5) 106 loading cycles, the degree will be:

$$
m_{2}=m_{1} \cdot \sigma_{-1 g} / \sigma_{a}
$$

reaching a value of about 15 .

Here:

$\sigma_{-1 g}$ - endurance limit of a steel part;

$\sigma_{a}$ - active tension in a dangerous section of the part.

Next, we consider an example and comparative analysis for a part with a fatigue life of steel St. 3, 15G and 15KHSND [6].

Strength (hardness) of steels is obtained by measuring selection of 50 samples.

Factory design organizations have only selective strength parameters and usually acting stresses recorded during strain gauging on one part and on one machine.

A transition has been made from sample hardness values (sample size $n=50$ ) to the aggregate using the graphical method and probabilistic grids for St. 3, 15G, 15KHSND (Fig. 1).

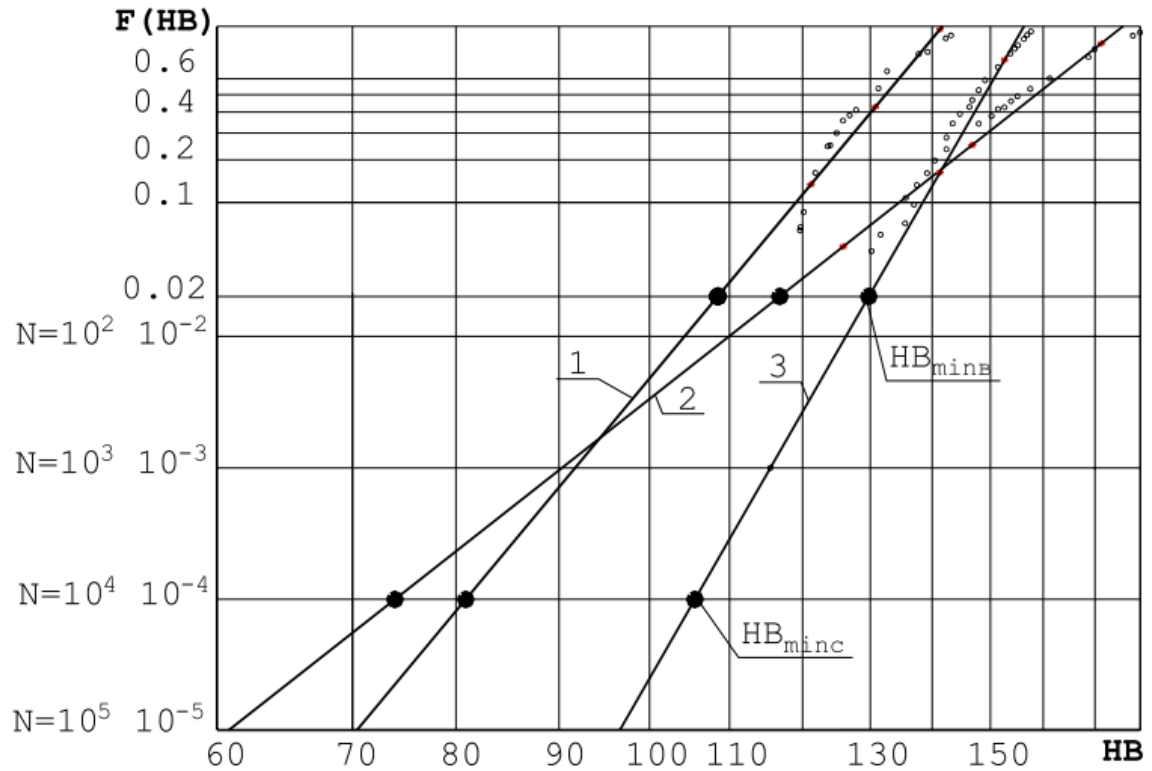

Fig. 1. The graphical method of transition from the sample to the aggregate for three grades of steel 1 - St. 3, 2 - 15G, 3 - 15HSND

Initial data on hardness and calculation results for three grades of St. 3, 15G, 15HSND are given in Table. 1.

Table 1. Calculation and experimental data on the hardness and resource of steel samples 


\begin{tabular}{|c|c|c|}
\hline \multicolumn{3}{|c|}{ St3 } \\
\hline Selection $\mathrm{n}$ & Set $\mathrm{Nc}$ & HBmin b \\
\hline 50 & 104 & 109 \\
\hline \multicolumn{3}{|c|}{$K_{H B \min }=\frac{H B_{\min } \mathrm{B}}{H B_{\min }}=\frac{109}{81}=1.34$} \\
\hline \multicolumn{2}{|c|}{$K_{T p \min }=K_{H B \min }^{m}=1.34^{6}=5.7$ times } & $T_{p \min }=\frac{20000}{57}=3508$ hours. \\
\hline \multicolumn{2}{|c|}{$K_{T p \min }=K_{H B \min }^{m}=1.34^{12}=33.5$ times } & $T_{p \min }=\frac{20000}{33.5}=597$ hours. \\
\hline \multicolumn{2}{|c|}{$K_{T p \min }=K_{H B \min }^{m}=1.34^{15}=80.6$ times } & $T_{p \min }=\frac{20000}{80,6}=248$ hours \\
\hline \\
\hline \multicolumn{3}{|c|}{$\begin{array}{l}\text { Steel 15G } \\
\text { Set Nc }\end{array}$} \\
\hline 50 & 104 & 118 \\
\hline \multicolumn{3}{|c|}{ in $=\frac{7}{7}$} \\
\hline \multicolumn{2}{|c|}{$K_{T p \min }=K_{H B \min }^{m}=1,59^{6}=16$ times } & $T_{\text {pmin }}=\frac{20000}{16}=1250$ hours. \\
\hline \multicolumn{2}{|c|}{$K_{T p \min }=K_{H B \min }^{m}=1.59^{12}=261$ times } & $T_{p \min }=\frac{20000}{261}=76$ hours \\
\hline \multicolumn{2}{|c|}{$K_{T p \min }=K_{H B \min }^{m}=1,59^{15}=1049$ times } & $T_{p \min }=\frac{20000}{1049}=19$ hours \\
\hline \\
\hline Selection $\mathrm{n}$ & \multicolumn{2}{|c|}{$\begin{array}{l}\text { Steel 15HSND } \\
\text { Set Nc }\end{array}$} \\
\hline 50 & 104 & 129 \\
\hline \multicolumn{3}{|c|}{101} \\
\hline \multicolumn{2}{|c|}{$K_{T p \min }=K_{H B \min }^{m}=1,21^{6}=3,1$ times } & $T_{p \min }=\frac{20000}{3,1}=6451$ hours. \\
\hline \multicolumn{2}{|c|}{$K_{\text {Tpmin }}=K_{H B \min }^{m}=1,21^{12}=9,8$ times } & $T_{p \min }=\frac{20000}{9,8}=2040$ hours \\
\hline \multicolumn{2}{|c|}{$K_{T p \min }=K_{H B \min }^{m}=1,21^{15}=17,4$ times } & $T_{p \min }=\frac{20000}{17,4}=1149$ hours \\
\hline
\end{tabular}

The results can be adjusted to determine the lower confidence limit for the first value of the variation series of samples.

For the aggregate of the final volume, for example, $\mathrm{Nc}=104$, the parameters of the threeparameter Weibull law were determined graphically using the previously obtained sample $\mathrm{HB}=20 ; \mathrm{b}=\mathrm{B} ; \mathrm{C}=\mathrm{Xmin}$, since the total value of Xmin cannot be less.

Some difficulty arose in determining the scale parameter $\mathrm{A}$ for the population. It turned out that Xmin can be defined in two ways: using an oblique line or a vertical line from point a. Then, using the formula: $\mathrm{X} \_\min =\mathrm{C}+\mathrm{A} \cdot \sqrt{ }(\mathrm{B} \&-\ln \mathrm{P})$, the $\mathrm{Xmin}$ values of the oblique straight line were found using the scale parameter $\mathrm{AN}=88 \mathrm{HB}$. X_min $=70+88 \cdot \sqrt{ }(4.8 \&$ $-\ln 0.9999)=83 \mathrm{HB}$; for a vertical straight line using the scale parameter $\mathrm{AB}=137 \mathrm{HB}$.

$X \_\min =70+137 \cdot \sqrt{ }(4.8 \&-\ln 0.9999)=90 \mathrm{HB}$.

Thus, the results obtained for Xmin are $83 \mathrm{HB}$ and $90 \mathrm{HB}$, i.e. they differ by $8 \%$.

Such a relatively small discrepancy allows using both values. 
To ensure a given resource of machine parts, it is necessary to have experimental (statistical) data on the distribution of their strength characteristics. An important characteristic for machine parts is their hardness.

For hardness measurements, a selection of 20 samples for St3 steel was formed $(n=20)$. Hardness measurements were carried out using a hardness tester (?). The data obtained are ranked and entered in the MS Excel table (Fig. 2).

When processing data from hardness measurements with Weibull distribution law and three parameters, the graphical method is used. The probabilistic grid is constructed so that the distribution function graph of hardness is a straight line. In block 5 of the algorithm (Fig. $1)$, the formula $\ln (-\ln (1-\mathrm{F}))=2.3 \mathrm{~b}(\log (\mathrm{x}-\mathrm{c})-\lg \mathrm{a})$ is used. The abscissa represents the value of the variable " $\mathrm{x}$ ".

\begin{tabular}{|c|c|c|}
\hline Test number & Hardness, HB & Variation Series \\
\hline 1 & 121 & 120 \\
\hline 2 & 138 & 120 \\
\hline 3 & 127 & 121 \\
\hline 4 & 120 & 122 \\
\hline 5 & 120 & 123 \\
\hline 6 & 125 & 124 \\
\hline 7 & 135 & 125 \\
\hline 8 & 132 & 126 \\
\hline 9 & 130 & 127 \\
\hline 10 & 143 & 130 \\
\hline 11 & 133 & 132 \\
\hline 12 & 147 & 133 \\
\hline 13 & 148 & 135 \\
\hline 14 & 141 & 138 \\
\hline 15 & 123 & 139 \\
\hline 16 & 150 & 141 \\
\hline 17 & 126 & 143 \\
\hline 18 & 122 & 147 \\
\hline 19 & 124 & 148 \\
\hline 20 & 139 & 150 \\
\hline
\end{tabular}

Fig. 2. Results of measuring the parts' hardness in MS Excel

(parts' hardness) in logarithmic coordinates, and along the ordinate axis the values of the distribution function F (Fig. 3) [5]. 


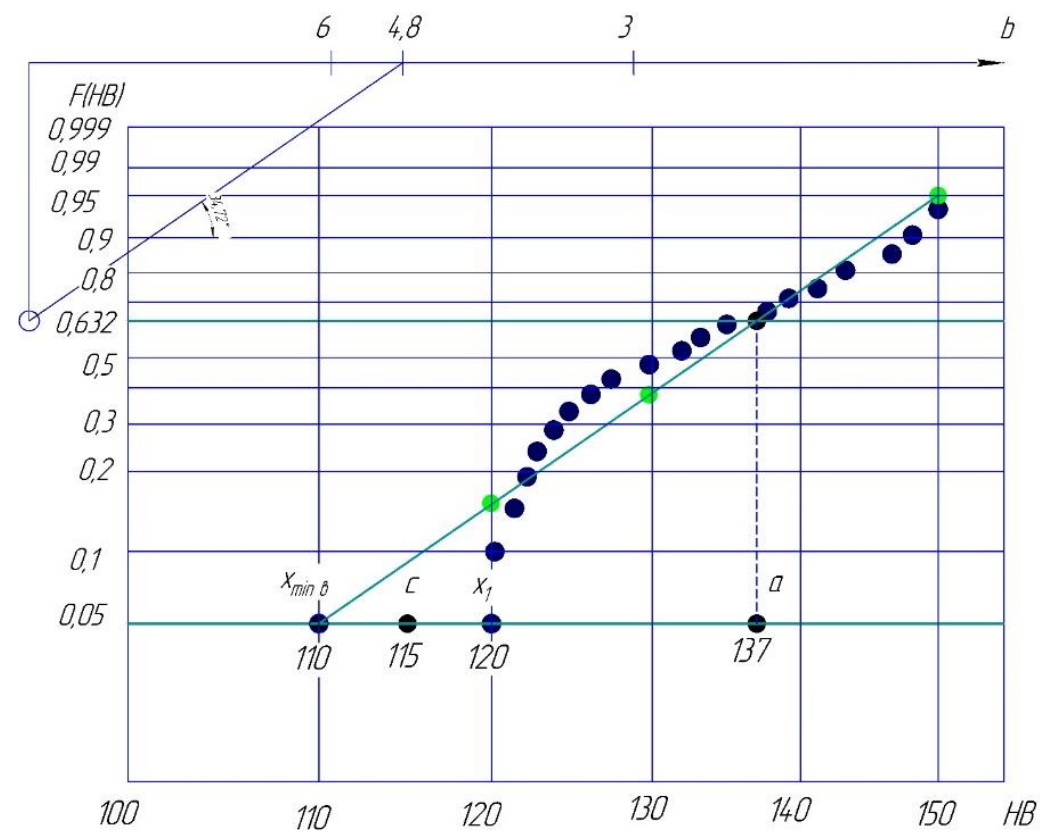

Fig. 3. Probability grid for the distribution of hardness for the sampling

\section{Summary}

The distribution parameters are determined: the scale parameter $\mathrm{a}$, the shape parameter $\mathrm{b}$, the shear parameter $\mathrm{c}$ and the minimum hardness value for $\mathrm{F}(\mathrm{x} 1)=0.05(\mathrm{n}=20)$ according to the sample data xmin $b=110$, which is $8.3 \%$ less than the first value of the variation series is $\mathrm{x} 1=120$.

The experimental data were approximated using the least squares method with a linear function, followed by extrapolation to the level $\mathrm{Nc}=104$ [6]. Thus, a linear distribution function of hardness is constructed from empirical points. (Fig. 3)

\section{References}

1. V.E. Kasyanov, T.N. Rogovenko, L.P. Schulkin, Bulletin of mechanical engineering, 10, 3-6 (2003).

2. V.E. Kasyanov et al., Bulletin of mechanical engineering, 10, 3-6 (2003).

3. T. N. Rogovenko, PhD Thesis (Rostov-on-Don, 1995).

4. V.E. Kasyanov, E.E. Kosenko, V.V. Kosenko, A.A. Kotesova, R.V. Khvan, Engineering Bulletin of the Don, 1 (2018).

5. V.V. Ivanov, S.I. Popov, A.V. Kirichek, Key Engineering Materials, 736, 18-22 (2017). DOI:10.4028/ www.scientific.net/ KEM.736.18

6. V.V. Ivanov, S.I. Popov, A.V. Kirichek, XI International Conference on Mechanical Engineering, Automation and Control Systems (MEACS 2017): IOP Conference Series: Materials Science and Engineering, 327 (2018). doi:10.1088/1757-899X/327/3/032026 